\title{
Analysis on the Judicial Interpretation of the Crawler Technology Infringing on the Intellectual Property Rights of Enterprise Data
}

\author{
Juan Yang ${ }^{1}$ \\ ${ }^{1}$ Sichuan Judicial and Police Officers Professional College, Deyang, Sichuan, 618000
}

\begin{abstract}
In the actual process of web crawler infringement and criminal identification, there is a theory of "weakening the infringement typology and strengthening the presumption of legal interest". This is also the basic method for the subsequent identification of infringement in the commercial application of enterprise data through crawler technology. This article summarizes the criminal risks of abusing crawler technology based on previous work experience. The author discusses the judicial interpretation of crawler technology infringing the legal benefits of corporate data intellectual property rights from the categories of data types crawled by various crawlers and the types of data crawled by crawlers determine the types of applicable laws, increase the concept of trade secrets, and determine the standards and other judicial interpretation clauses three sides.
\end{abstract}

\section{INTRODUCTION}

The commercialization of enterprise data has caused many illegal activities, and ultimately led to huge economic losses. From a technical perspective, web crawlers are the core of this technology, and are also called "robots" in some literature. In addition, web crawling technology is the basic technical content of the Internet. Various data-based companies often apply it to Internet scenarios, which can achieve in-depth crawling of web page data. However, some illegal operations have brought huge maintenance pressure to the website, and in severe cases, the server may crash and the related work cannot be continued.

\section{The Criminal Risk of Abusing Crawler TECHNOLOGY}

\subsection{Abusing Crawler Technology to Violate Personal Information Rights}

At this stage, it is relatively common for personal data to be illegally collected and traded on the Internet. From a technical point of view, many crawler programs will work according to the designer's ideas, and their non-autonomous and purely technical characteristics are more obvious. Under certain conditions, web crawlers will be triggered. It will perform automated data capture operations, and then technicians will collect data in a reasonable manner. For example, some companies use legal means to obtain login permissions when providing commercial services, and then implant information stealing programs. Eventually, it will obtain a large amount of valuable personal information and store it in domestic and foreign servers. This process of screening personal information with a web crawler does not remind the user that the information has been collected and used by others, which violates the legal provisions of the user's knowledge and consent. Although China has repeatedly adjusted the text content of the application software privacy policy, there are still some problems such as advertising push and data sharing in many aspects [1].

\subsection{Abusing Crawler Technology to Pollute the Business Environment}

From the perspective of the operation of certain business models, the main purpose of crawler technology is to obtain login credentials and information in the operator's server, and use this to control social accounts to add fans and visit promotional web pages, and obtain network marketing expenses from it. At the same time, many data information, such as account passwords, personal information, etc., will be stored on the operator's server when the Internet account is online. After that, this information will be processed into various data products. The enterprises involved in this type of case will establish normal cooperative relations with Internet operators, and use this to obtain the operators' commercial service contracts and server remote login permissions. Afterwards, it will place the data collection crawler on the operator's server without the operator's knowledge. In this way, data collection behavior that exceeds the authority will occur, which violates the contractual agreement with the operator, and thus pollutes the entire business environment, which is extremely harmful to the society. The flow chart of the crawler system is shown in Figure 1. 


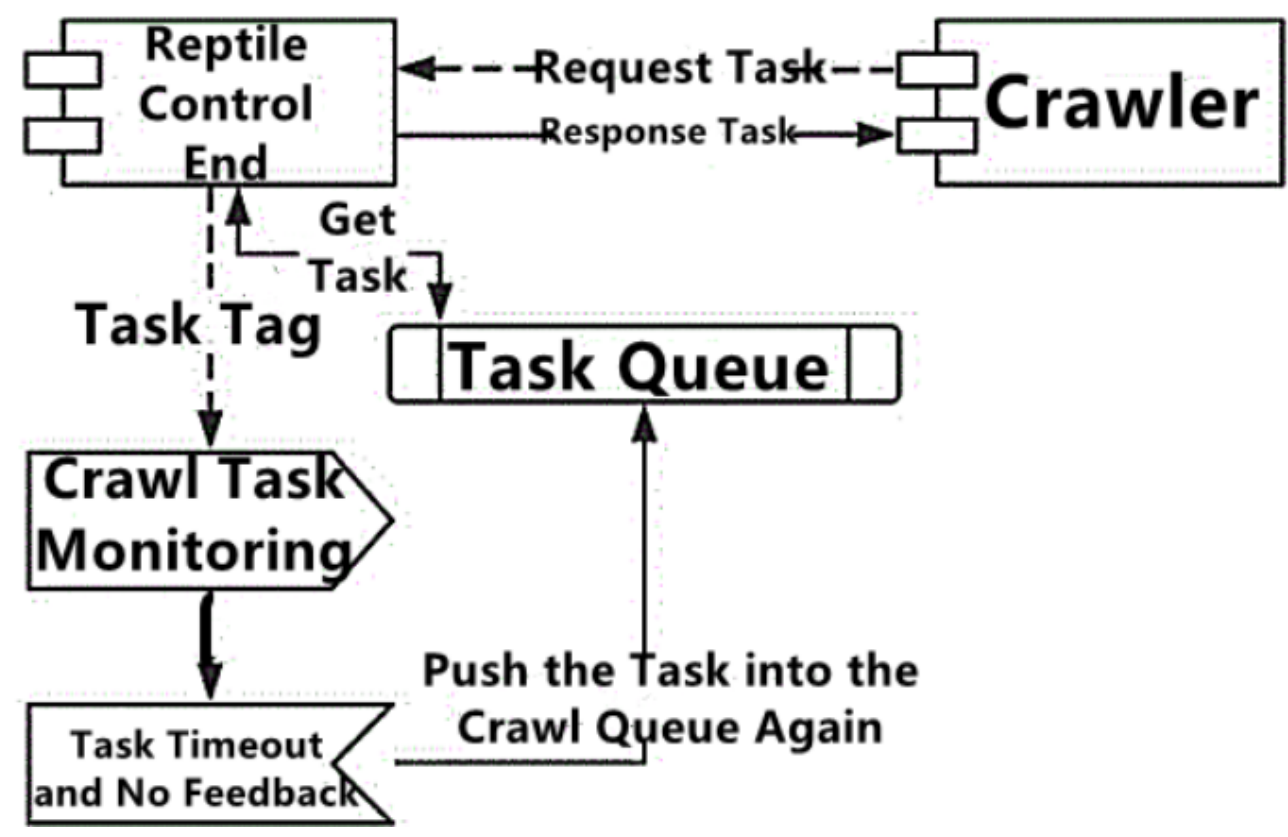

Figure 1. A Flow Chart of Crawler Technology Application

\subsection{Illegal Circulation of Electronic Data and National Security and Public Safety}

In the information age, the state is not only an information governor, but also a user and processor of important personal information. In the newly revised "National Security Law of the People's Republic of China", China first proposed the concept of "cyberspace sovereignty", which is very different from the traditional concept of national security. That is, network information security is a non-traditional national security content, and the actual concept of sovereignty in the National Security Law is also a derivative of the traditional concept of national sovereignty. For example, if a large amount of personal data is used by hostile forces or criminal groups, the entire country and public security will be greatly affected. Up to now, there have been many online user information leaks in China. Offenders mainly use big data technology to analyze different data sources. It can obtain multi-dimensional portraits of users, which affects the stable development of society.

\section{LEGAL BENEFITS INTERPRETATION OF ENTERPRISE DATA INTELLECTUAL PROPERTY}

\subsection{The Judicial Dilemma that Corporate Data is Difficult to Categorize and Violates Commercial Property Interests}

\subsubsection{The Dilemma of Property Interest Classification}

Whether enterprise data itself can be regarded as property, relevant departments have been unable to give a clear definition. Moreover, from the perspective of the broader concept of data, even if it is regarded as property, many complex issues are involved. In contrast, the relationship between data object and property is close to the relationship between property and object of civil law. There are not only obvious differences, but they can also be linked to each other. Generally speaking, the problem of object has always been obvious, and it has obvious characteristics of civil law construction. In contrast, the issue of property is more complicated and troublesome. From the perspective of the three conceptual attributes of property at this stage, except to directly incorporating this type of vegetable market into the property law, it can also be regarded as a property right in the civil law. But the abstract features are very obvious, which makes the content of the property more difficult to control. In the development of modern society, virtual property has gradually been recognized by the public. Although the objectivity problem of data itself has not been solved, it can play an active role in the era of big data, which can solve the problem of economic use of data using property law. This can also help companies establish corresponding data laws and regulations, and the effect is very obvious. In fact, the application of property law or tort law is not yet clear. In most cases, the state needs to ensure that the protection of absolute rights in the property law maximizes the benefits [2].

\subsubsection{The Dilemma that Corporate Data is Difficult to Classify A Specific Property Attribute}

The form of legal interest mainly includes rights, security and order, which is also a common type of infringement of the legal interest of corporate data. Among them, rights mainly include personal rights and property rights, security represents national security and public security, and order refers to economic order and social order. In contrast, the infringement of intellectual property legal interests is far more specific than the security legal interests, and the actual identification standards represent 
basic property attributes. In general, property crimes and personal crimes are more common. The property attributes involved in these data crimes mainly refer to the criminal property legal interests of corporate data. It can be seen from the content of civil law that the main object of protection is the property attribute, that is, the legal interest of civil property. Besides, the property attribute under the protection of civil law is very close to the legal interest of civil property. The property attribute protected by civil law is the legal interest of civil property. The data civil property attribute is the property attribute that belongs to the civil law system to realize self-presentation through the data model as a medium. The legal interest of corporate data property is a new type of protection of legal interest. The scope of protection and the purpose and tasks of protection are uncertain, and there is no clear stipulation in the laws of various departments in China.

\subsection{It is Difficult to Balance the Judicial Dilemma Between the Expansion of the Protective Function of the Criminal Law and the Legal Punishment}

At this stage, network security has become an important part of the country's modern development. If there is crawling behavior in cyberspace, it may cause damage to personal rights. This will affect the right to free management and waste a lot of traffic and resources. Otherwise, this will also pose a great threat to the country's modern governance while maintaining the development of the Internet industry. Relevant data shows that, so far, more than half of crawlers crawling corporate data belong to the category of malicious behavior. Affected by malicious crawlers, criminals can use the data obtained from the site at will. After that, it will transfer the site data content to other sites, and will not display the data source or the remark link. Furthermore, many fake websites have been established under the action of these illegal web crawling methods. This will give rise to a lot of fraud, and even steal intellectual property and trade secrets. It can be seen from the above-mentioned bad web crawling behaviors that corporate data rights are easily violated, and relevant companies need to further increase their attention [3].

\subsection{Difficulty in Determining the Criminal Motive and Conviction}

Web crawlers mainly refer to the corresponding Internet interaction with the help of computer technology, which can truly collect, process and share data. In fact, there are also big differences between web crawlers and hacking. Hacking behavior mainly includes destructive behavior and non-destructive behavior. Among them, non-destructive behavior is mainly organized by means of interfering with the system to information bombs. This is not data theft in the general sense. In addition, the most serious hacking behavior is the direct theft of information data or the destruction of system data. It can also be seen from this that hackers are disrupting programs, while crawlers represent money-seeking tools. In fact, reptiles themselves are not criminal means, they are only tools of criminals. In the early days of abuse, computer technology was mainly in the form of snooping and joking, while hackers disrupted the order of social management. However, with the development of technologies such as cloud computing and big data, crawler technology has also been upgraded to the pursuit of data benefits. Besides, the difference between web crawlers and hacking is in the direction of the object itself. In terms of the actual network service agreement, it also needs to meet the national informatization management regulations, giving the relevant state agencies more supervisory powers and methods. This can avoid causing more problems [4].

\section{PRINCIPLES AND RULES FOR THE Protection OF CoRPorate DATA INTELLECTUAL PROPERTY RIghtS}

\subsection{Infringement of the Legal Principles of Intellectual Property Protection}

From the perspective of the socialization of law, the implementation of the actual protection of intellectual property laws is conducive to the overall protection of intellectual labor results and the overall maintenance of the order of competition. In the development process of the past few decades, China has gradually improved the design of its intellectual property legal system. Its innovation is obvious, and the actual intellectual property system has begun to conform to international standards in many aspects. Since the era of informatization and globalization, the object of intellectual property has become more diverse and complex, which has also put forward more requirements for the protection of intellectual property, and the extension of the object has become wider and wider. Therefore, people need to fully consider the legal benefits of intellectual property rights and implement the principle of statutory crimes in criminal legislation. Actual intellectual property rights should be based on the principle of statutory crimes as the main body in criminal legislation activities and strengthen the protection of intellectual property rights in criminal law. In fact, the subject of intellectual property involves a lot of economic activities, and there are many complicated social relations in terms of subject and object, and it cannot be determined as legal or illegal in a short time. To this end, relevant staff need to proceed from the perspective of scientific rationality, first using non-criminal laws for orderly regulation. After entering the era of "knowledge payment", the economic benefits involved in high value-added intellectual achievements have become more obvious. People need to increase the scope of intellectual property protection and the threshold of conviction to increase the cost of crime.

\subsection{Rules for the Protection of Legal Interests of Enterprise Data Intellectual Property Rights}

The research community has two different views on the mutual complementation and protection of intellectual 
property law and anti-unfair competition law. The first argument is that supplementary protection is limited protection, and that the content in the anti-unfair competition law should be based on the premise that it does not contravene the intellectual property legislation and policies to carry out corresponding extended protection operations. The extension line theory mainly comes from Japan's extension line theory of tort law. The second argument is that the supplementary protection theory is the bottom protection theory. The doctrine clearly states that intellectual property law and anti-unfair competition law are equally incompatible. Intellectual property law mainly defines a group of rights in intellectual property, but the boundaries are relatively clear. Otherwise, intellectual property relaxationism is mainly a set of legal benefits of intellectual property behaviors, which will achieve typified development with the power of property rights. It can be seen from the above content that the criminal law setting of crawling behavior in the era of big data needs to update the traditional closed mode of intellectual property protection to increase the penalties for illegal acts. This can provide effective protection for infringement of intellectual property rights [5].

\section{JUDICIAL INTERPRETATION OF CRAWLER TECHNOLOGY INFRINGEMENT OF CORPORATE DATA INTELLECTUAL PROPERTY RIGHTS}

\subsection{Categories of Data Types Crawled by Various Crawlers}

From the perspective of the types of data obtained by crawlers, the first category is personal data, which mainly refers to information about natural persons that have been identified or can be identified. Among them, in the research of "personally identifiable information", the data set does not need to involve the names and detailed information of natural persons, which can also ensure that the application of these data is clearly identifiable. If other information cannot be "supplemented", but user data can still be identified, it represents non-personal data. Another type of data is enterprise data, which is mainly related to business operators such as business data, research results and other data content. This also includes authorized collection and personal-related data content. This part of user personal information related data can provide personalized and customized services for enterprises. But if companies use these data indiscriminately, personal data will also be leaked, infringing on personal privacy. The third type of data is public data, which mainly refers to the data generated when the administrative agency performs its functions. This also involves medical data, traffic data and so on. These data are also related to personal factors, which should be protected by relevant departments.

\subsection{The Type of Data Crawled by the Crawler Determines the Type of Applicable Law}

\subsubsection{Protect Personal Data in Accordance with Personal Privacy Laws}

From a broad perspective, personal data mainly refers to all information that helps natural persons identify the data subject. In terms of actual personal data protection, the constitutions of various countries do not provide for information privacy and data, but some countries have issued the General Data Protection Regulations. This content can ensure that citizens and residents protect their own data ownership and avoid deliberate or negligent problems. For reptiles stealing personal data, high fines will be imposed. In addition, in the selection of data rights subjects, individuals can transfer data rights to enterprises. In this way, it can ensure that the company provides personalized services to individuals.

\subsubsection{Rely on Technical Contracts to Restrict Data Crawling Behavior}

The value application of enterprise data is mainly its own data utilization and transaction process. In general, crawling companies to collect data should sign a technical contract with the data owner. At this stage, with the continuous development of Internet companies, mobile phones and laptops are becoming more and more advanced. These devices often require GPS support and collect personal data when applying various programs. In addition, the popularity of cloud computing big data services allows security service providers to collect more data. This leads to a rapid increase in data flow. At this time, data analysis methods also need to be updated to predict user behavior and habits. Companies can also accept the relevant format clauses to ensure that personal data is used for authorized operations. At this time, the company should use computer technology to authorize the collected personal data to be desensitized, and the property rights of the final data products should belong to the company. It should be noted that companies must not infringe on the personal rights of users in these data applications. Only by guaranteeing this premise, can companies allow crawling data to draw up relevant contracts, perform subsequent transaction operations, and reduce the probability of infringement problems [6].

\subsubsection{Added Judicial Interpretation Clauses such as the Concept of Trade Secrets and Identification Standards}

It can be seen from the previous enterprise development that most of the data infringement is mainly in the form of crawling the database, after which it will obtain more economic benefits through specific data content. Data breaches cause material and non-material losses. It may be money, or it may be in an intangible state such as corporate competitive advantage. In terms of data information, it is also difficult to carry out valuation operations. The actual judicial interpretation can be 
carried out through the "Copyright Law", and the final compensation amount can be determined, but it can also be determined based on factors such as the actual data and the user's benefits. If the company's infringement is serious, you can refer to the relevant handling regulations of other countries. In legislation, trade secret infringement and copyright are obviously different. Infringers need to obtain information content in a certain form, but not all are treated as infringements. Relevant data shows that the determination of facts of infringement of trade secrets is far lower than that of copyright infringement. In terms of judicial practice, the probability of the infringee winning the case only accounts for $9.27 \%$ of all cases.

\section{CONCLUSION}

In summary, relevant companies should do a good job in the classification of their own data in the development process. Relevant companies need to extract specific property legal benefits from actual data property rights, and clarify specific intellectual property legal benefits. Subsequently, relevant industries should conduct reservoir deduction and establish the best problem-solving model. Furthermore, in the security maintenance of corporate data and intellectual property rights, relevant companies should ensure that the protection of existing intellectual property rights is distinguished from judicial interpretation and establish the best judicial practices.

\section{REFERENCES}

1. Yang Zhiqiong. The Criminal Regulations of Web Crawlers in the Data Age[J]. Comparative Law Research, 2020(04):185-200.

2. Fang Peng. Discussion on the application of web crawler technology in commercial banks in the era of big data[J]. Smart City, 2019, 5(23): 26-27.

3. Wang Meizhi, Zhi Xuechao, Liu Caihui. Design and implementation of multithreaded focused web crawler based on Python[J]. Journal of Gannan Normal University, 2019, 40(06): 35-38.

4. Miao Zhi, Ren Minmin. Practical exploration of web crawlers in public opinion monitoring $[\mathrm{J}]$. Computer Knowledge and Technology, 2019, 15(19): 46-47.

5. Hu Shaoyu, Liu Zhimin, Dong Ke. Precise investment promotion under the web crawler technology in the era of big data and digital media[J]. Electronic Technology and Software Engineering, 2019(05):4-5.

6. Zhang Zheng. On the application of web crawler technology in commercial banks in the era of big data $[\mathrm{J}]$. Computer Products and Circulation, 2019(02):144. 